\title{
Diabetes related knowledge, self-care behaviours and adherence to medications among diabetic patients in Southwest Ethiopia: a cross-sectional survey
}

\author{
Tefera Kassahun ${ }^{1}$, Hailay Gesesew ${ }^{2,3^{*}}$, Lillian Mwanri ${ }^{3}$ and Tesfahun Eshetie ${ }^{4}$
}

\begin{abstract}
Background: The provision of health education involving self-care and good adherence to medications has been acknowledged to be a cost effective strategy for improving quality of life of diabetes patients. We assessed levels of knowledge about type 2 diabetes mellitus (T2DM), self-care behaviours and adherence to medication among DM patients.

Methods: A facility based cross-sectional survey of 325 adults with T2DM patients attending Jimma University Teaching Hospital, Southwest Ethiopia was conducted. We used diabetes Knowledge Test, Expanded Version of the Summary of Diabetes Self-Care Activities and Morisky 8-Item medication adherence as tools to measure diabetic knowledge, self-care behaviours and adherence to medications respectively. Multinomial logistic regression analyses were used to assess the independent predictors of diabetes knowledge and adherence to medications. The binary logistic regression was applied for self-care behaviours.

Results: 309 respondents were included in the survey. Of all the respondents, $44.9 \%, 20.1 \%$ and $34.9 \%$ had low, medium and high level diabetic knowledge respectively. High level of diabetic knowledge was the reference group. Being illiterate ( $A O R=3.1,95 \% \mathrm{Cl}$ : 1.03-9.3), having $\mathrm{BMl}<18 \mathrm{~kg} / \mathrm{m}^{2}$ ( $\mathrm{AOR}=6.4,95 \% \mathrm{Cl}: 1.2-34.9$ ) and duration of $\mathrm{DM}<$ 5 years ( $\mathrm{AOR}=4.2,95 \% \mathrm{Cl}: 1.9-9.5)$ were significantly associated with low level of diabetic knowledge. T2DM patients who practiced good self-care ( $A O R=0.5,95 \% \mathrm{Cl}$ : 0.3-0.9) were less likely to have low knowledge. Duration of $\mathrm{DM}<5$ years $(A O R=9.8,95 \% C l: 3.2-30.2)$ was significantly associated with medium level of diabetic knowledge. 157(50.8 \%) patients had poor self-care behaviour and this was associated with level of education and adherence to medication. The proportions of patients with low, medium and high adherence to medication were $24.9 \%, 37.9 \%$ and $37.2 \%$ respectively. Being a merchant, having medium level of diabetic knowledge and having good glycemic control level were associated with low adherence to medications.

Conclusions: Significant number of DM patients had low level of knowledge, poor self-care behaviours and low level of adherence to medications. These findings call for the need of integrated interventional management on diabetic knowledge, self-care behaviours and adherence to medications. To ensure effective T2DM management, a strategic approach that improves health literacy could be a cross cutting intervention.
\end{abstract}

Keywords: Knowledge, Self-care behaviour, Adherence, Type 2 diabetes mellitus, Ethiopia

\footnotetext{
* Correspondence: hailushepi@gmail.com

${ }^{2}$ Department of Epidemiology, College of Health Sciences, Jimma University,

Jimma, Ethiopia

${ }^{3}$ Discipline of Public Health, Faculty of Medicine, Nursing and Health

Sciences, Flinders University, Adelaide, Australia

Full list of author information is available at the end of the article
} 


\section{Background}

Diabetes mellitus (DM) is a serious global public health problem, an illness that kills silently. In 2013, it was reported that DM killed 4.6 million people, [1] with further 387 million reported to being affected in 2014 [2]. More than $77 \%$ of morbidity [2] and $88 \%$ of mortality [3] resulting from DM occurred in low- and middle- income countries in 2012. Diabetes mellitus scourge is expected to affect nearly 592 million people globally by the end of 2035 [2]. In Ethiopia, the prevalence of diabetes was $3.5 \%$ in 2011, [4] and the extrapolated prevalence in 2013 was $4.36 \%$ [2]. Reportedly, 34,262 patients out of 1.8 million DM cases died in Ethiopia in 2013 [2]. It is also known that a large number of people remain undiagnosed, with estimated number of undiagnosed cases reported to be 1.39 million people in 2013 [2]. Type 2 diabetes mellitus (T2DM) is the most common form of DM worldwide, accounting for more than $90 \%$ of cases [1].

Diabetes is a chronic disease significantly affecting the quality of life of affected populations and can lead to poor health outcomes of individuals, families and communities [5]. Its impact affects social and economic outcomes, [6] including costing millions of health care budgets of nations [2] across the world [7]. The risk factors for DM include raised blood pressure, tobacco use, alcohol consumption, physical inactivity, poor dietary patterns and overweight $[8,9]$. Poor adherence to medications and poor self-care behaviours have also been reported to be barriers for effective management of DM complications $[8,10]$. Most of the risk factors of DM and its complications are modifiable. Self-management strategies such as self-monitoring of blood glucose, dietary restrictions, regular foot care and ophthalmic examinations have all been shown to markedly reduce the incidence and progression of DM complications,[1] and these can be achieved by patients themselves via effective education and enhanced knowledge [11].

Evidences from earlier studies have supported the notion that having good knowledge and education have influence to good care and can reduce DM complications significantly $[12,13]$. Knowledge not only enhances the self-care behaviours [1], but it enables DM patients to adhere to their treatment effectively. It has also been noted that age, lack of resources and perceived side effects have significant association with poor adherence to medication [8].

Knowledge, self-care behaviours and adherence to medications in diabetes could be helpful for early case detection, prevention, and minimization of complications, and improvements of the quality of life of affected individuals. Previous studies have reported poor health outcomes to be associated within insufficient knowledge, poor self-care behaviours and adherence to medications among diabetic patients [14-16]. There is insufficient work regarding knowledge, self-care behaviours and adherence to medications related to DM in Ethiopia. Studies to provide evidences for these factors are noteworthy for prevention and control of diabetes and other noncommunicable diseases (NCDs), and to inform policies and strategies in such resource meager countries. We assessed the levels of knowledge, self-care behaviours and adherence to medications about diabetes mellitus among diabetic adult patients in Ethiopia.

\section{Methods}

\section{Study design, settings and participants}

A facility based cross-sectional study was carried out in diabetic clinic at Jimma University Teaching Hospital (JUTH), Southwest Ethiopia between February and April 2014. We followed Drug Administration and Control Authority of Ethiopia guidelines [17] for diagnosis and classification of DM. These guidelines are similar to the criteria developed by International Diabetes Federation (IDF) [18]. The study was conducted among T2DM adult patients ( $\geq 18$ years) who were for at least four visits.

This work was conducted alongside our previously published paper on glycemic control [19]. Originally, the project had four outcomes: glycemic control, knowledge, selfcare behavior and medication adherence. The sample size calculation considering all outcomes and 'glycemic control' gave us the maximum sample size that helped us to look at various factors that affect the outcomes. The sample size was calculated via OpenEpi 2.3 software using a single population proportion calculation formula using the following assumptions: $58.2 \%$ proportion [8], $95 \%$ confidence level, $5 \%$ margin of error and $10 \%$ non-response rate. Considering a correction formula, the total calculated sample yielded 325. Using sampling frame of DM records, simple random sampling technique was used to recruit the study participants (Fig. 1).

\section{Dependent variables}

Diabetes knowledge, self-care behaviours and adherence to medications were the dependent variables. Diabetes Knowledge was measured using The Diabetes Knowledge Test (DKT) [20, 21]. The DKT was developed and tested for reliability and validity by the University of Michigan scholars and was adapted for the Ethiopian context. The DKT is a 23-item multiple-choice test designed to assess knowledge about diet, exercise, blood glucose levels and testing and self-care activities. Each item had three or four multiple choices with only one correct answer. The first 14 items were designed for all adults with diabetes, while items 15-23 apply only to those using insulin [21]. Scores on the DKT were 


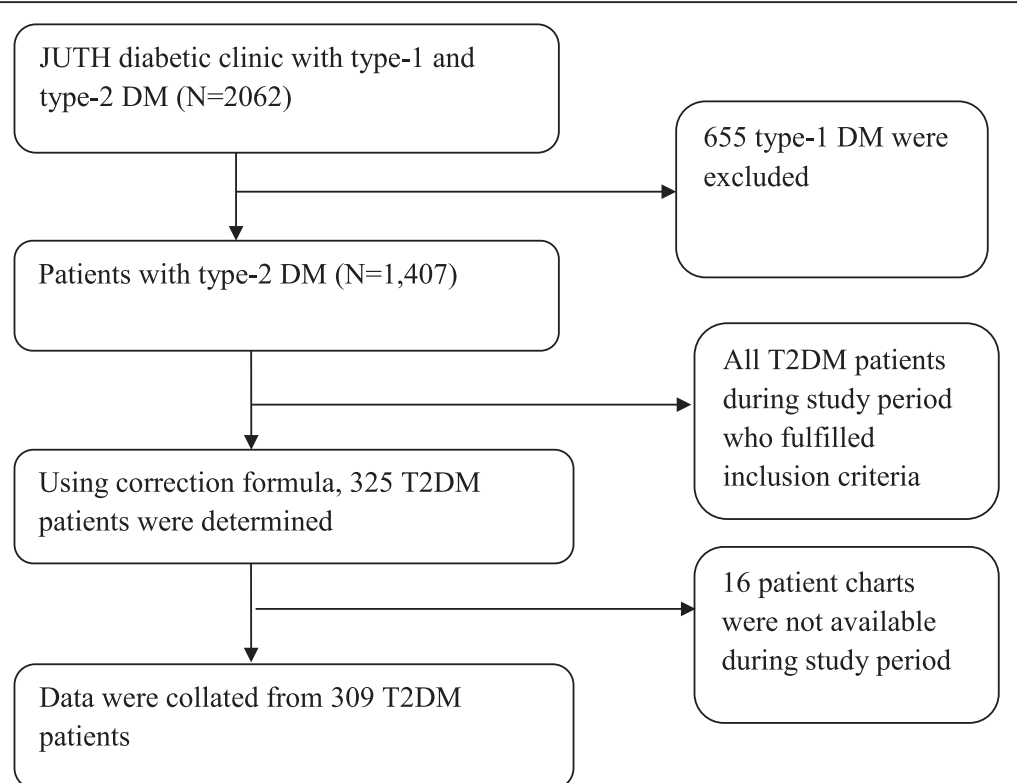

Fig. 1 Summary of flowchart record selection, 2014

computed for each participant. The score was determined by dividing the number of correct answers by the total number of questions (23 questions for patients taking insulin and 14 for those receiving oral hypoglycemic agents). Scores $\geq 75 \%, 74-60 \%$ and $\leq 59 \%$, respectively, were labeled as high, medium and low knowledge on diabetes [20]. Internal consistency of the tools for knowledge was measured by Cronbach's alpha and was adequate (Cronbach's alpha $=0.78$ ).

Self-care behaviours were assessed using Expanded Version of the Summary of Diabetes Self-Care Activities (SDSCA) [22]. The SDSCA was originally developed from "The Summary of Diabetes Self-Care Activities Measure" that resulted from seven studies carried out by scholars from Oregon Research Institute, United States. The tools were adapted for the Ethiopian Context. We adapted some foodstuffs, for instance high fat diet food types, and terminologies mentioned in the original version to fit Ethiopian context. Each scale measured frequency of self-care activity in the last 7 days for the following aspects of the diabetes regimen: general diet, foot-care, exercise and medication taking. The score was presented in terms of mean number of days for each self-care behaviours, which was calculated by summation of number of days of self-care practice divided by total number of patients. The overall mean score was calculated by summation of the mean score for diet, footcare, exercise and medication taking divided by the sum of number of questions under each scale. After calculating an overall mean score, it was classified as having good self-care behaviour if the patient scored $\geq 3$ or poor self-care behaviour if the patient scored $<3$.
Adherence to medications was measured using Morisky scale [23] that was prepared from "Concurrent and predictive validity of a self-reported measures of adherence to medications". The tool was originally developed by scholars from the University of California, University of Texas and John Hopkins Research institute, but again adapted for Ethiopian use. It consisted of 8-item questionnaire with yes or no responses coded respectively as 1 or 0 . But for one question, the score was given inversely. The total score of adherence to medications was classified in to low adherence if the score was $>2$, medium adherence if between 1 and 2 , and high adherence if 0 .

\section{Independent variables}

The explanatory variables included: socio-demographic and economic data (age, sex, education level, marital status, occupation, income, ethnicity and religion), history of smoking, history of alcohol consumption, family history of DM, duration of therapy, body mass index (BMI) and glycemic control level. Level of education was classified as illiterate (couldn't read and write), primary (received education up to class eight), and secondary and above (received education class from grade nine and above).

History of smoking and history of alcohol consumption has been assessed as during lifetime. We asked participants to report their lifetime experience of cigarette smoking and alcohol drinking. We recorded their response as smoker, non-smoker and ex-smoker for cigarette smoking whereas for alcohol drinking we asked their status as drinker or non- drinker. For statistical 
analysis, we further aggregated their responses to yes or no binary responses. Family history of DM was measured if any family member (mother or father) had DM. Anthropometric measurements were used to assess the body mass index (BMI). Glycemic level was coded as poor or good. Poor glycemic control was defined if fasting blood glucose (FBG) level was above $130 \mathrm{mg} / \mathrm{dl}$. Patients FBG reading for at least four months were recorded and the mean blood glucose level computed [24].

\section{Interviews}

Six face-to-face interviews were conducted by six registered nurses and one public health officer to solicit socio-demographic and economic data, medication adherence, diabetic knowledge and self-care behavior of participants. The interviews were conducted in a quiet room at the DM clinic where patients came for follow up checkup. Validated and structured interviewer rater questionnaires were used for data collection. The Morisky medication adherence scale questionnaires was used to solicit participants' adherence to taking medications, whereas Expanded Version of the Summary of Diabetes Self-Care Activities (SDSCA) Self-care behaviours questionnaire were used to assess participants self-care behavior adherence. The Diabetes Knowledge Test (DKT) tool, a 23 multiple-choice question test was used to measure participants' diabetes knowledge. The tools were firstly designed in English and then translated in Amharic and Afan Oromo (local languages), and again back translated into English by experts who had similar experiences (Additional file 1). Questionnaires were pretested with diabetic patients in another nearby hospital at Jimma and necessary modifications were made.

\section{Statistical analysis}

Descriptive statistics included mean, median, standard deviations, and range values for continuous data; percentage and frequency tables for categorical data. We used multinomial logistic regression to analyze factors that were associated with diabetes knowledge and adherence to medications. To assess factors associated with self-care behaviours, binary logistic regression analysis was used. For both multinomial and binary logistic regression analyses, bivariate and multiple regression assessment was conducted to check the existence of crude association and select the candidate variables $(P<0.25$ was considered).

We checked multi-collinearity among selected independent variables via variance inflation factor (VIF) and none was found. $P$-value $<=0.05$ was considered as a cut off point for statistical significance in the final model. Fitness of goodness of the final model was checked by Hosmer and Lemeshow and was found fit.
The Data were summarized using odds ratio (OR) and $95 \%$ confidence interval. The analyses were conducted in Statistical Package for the Social Sciences (SPSS) version 22.0 for mackintosh.

\section{Results}

\section{Socio-demographic and clinical characteristics of respondents}

Three hundred and twenty five (325) DM patients were considered eligible, but 16 were excluded because their charts were not available (Fig. 1). In total, 309 (95 \%) patients were included in the analysis.

Table 1 shows demographic characteristics of the respondents. Males were over-represented (61.8 \%) and almost two fifth $(36.9 \%)$ of the respondents represented the age group 51-60 years. Nearly half $(46.6 \%)$ of the respondents followed Muslim religion and four out of five $(81.2 \%)$ respondents were married. Two fifth

Table 1 Frequency distributions of socio-demographic characteristics of T2DM patients on follow up at JUTH, 2014

\begin{tabular}{|c|c|c|}
\hline $\begin{array}{l}\text { Socio-demographic } \\
\text { characteristics }(n=309)\end{array}$ & Categories & n (\%) \\
\hline \multirow[t]{2}{*}{ Sex } & Male & 189 (61.8) \\
\hline & Female & $120(38.2)$ \\
\hline Age & $\begin{array}{l}<40 \text { years } \\
40-60 \text { years } \\
>=60 \text { years } \\
\text { Missing }\end{array}$ & $\begin{array}{l}12(3.9) \\
188(60.8) \\
87(28.2) \\
22(7.1)\end{array}$ \\
\hline \multirow[t]{3}{*}{ Marital status } & Married & $251(81.3)$ \\
\hline & Single & $21(6.8)$ \\
\hline & Widow/er & 37 (11.9) \\
\hline \multirow[t]{7}{*}{ Ethnicity } & Oromo & $170(55.0)$ \\
\hline & Amhara & $78(25.2)$ \\
\hline & Keficho & $21(6.8)$ \\
\hline & Gurage & $10(3.2)$ \\
\hline & Dawero & $8(2.6)$ \\
\hline & Yem & $8(2.6)$ \\
\hline & Other $^{a}$ & $14(4.5)$ \\
\hline \multirow[t]{2}{*}{ Religion } & Muslim & $144(46.6)$ \\
\hline & $\begin{array}{l}\text { Orthodox } \\
\text { Protestant } \\
\text { Others }^{b}\end{array}$ & $\begin{array}{l}138(44.7) \\
23(7.4) \\
4(1.3)\end{array}$ \\
\hline Level of education & $\begin{array}{l}\text { Illiterate } \\
\text { Primary } \\
2^{0} \text { and above }\end{array}$ & $\begin{array}{l}109(35.3) \\
112(36.3) \\
88(28.4)\end{array}$ \\
\hline \multirow[t]{5}{*}{ Occupation } & Employed & $72(23.3)$ \\
\hline & Unemployed & $78(25.2)$ \\
\hline & Merchant & $29(9.4)$ \\
\hline & Farmer & $94(30.4)$ \\
\hline & Daily labor & 36 (11.7) \\
\hline
\end{tabular}

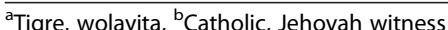

T2DM type 2 diabetes mellitus, JUTH Jimma University Teaching Hospital 
(36.2\%) respondents attained grades $1-8$, and $30.4 \%$ of respondents were farmers.

\section{Level of knowledge on diabetes}

Table 2 shows the distribution of subjects' knowledge of diabetes by demographic and clinical characteristics. Among the patients, $44.9 \%, 20.1 \%$ and $34.9 \%$ had low, medium and high level of knowledge of diabetes respectively. For respondents who had low level of knowledge of diabetes, $30.9 \%$ had low adherence to medications, $56.1 \%$ had poor self-care behaviours and $28.1 \%$ had poor glycemic control level. Similarly, among those who had medium knowledge level, $33.9 \%$ had medium adherence to medications level, $41.9 \%$ had poor self-care behaviour and $38.7 \%$ had poor glycemic control. Those respondents who had high knowledge level of DM, $25 \%$ had low level of adherence to medications, $43.5 \%$ had poor self-care behaviour and $25 \%$ had poor glycemic control level.

Table 2 also presents results of the multinomial logistic regression analysis of factors associated with knowledge of diabetes. High level of knowledge of diabetes was the reference group. Illiterate respondents compared to those who attained higher secondary education were highly likely (AOR $=3.1,95 \% \mathrm{CI}$ : 1.03-9.3) to have low level of knowledge. The relative probability of having a low level of knowledge among respondents who had BMI below $18 \mathrm{~kg} / \mathrm{m}^{2}$ was significantly higher $(A O R=$ 6.4, 95\%CI: $1.2-34.9)$ than those who had $30 \mathrm{~kg} / \mathrm{m}^{2}$ and above. Duration of DM of less than five $(<5)$ years was associated with both low level of knowledge $(\mathrm{AOR}=4.2$, 95\%CI: 1.9-9.5) and medium level of knowledge of diabetes $(\mathrm{AOR}=9.8,95 \% \mathrm{CI}: 3.2-30.2)$.

\section{Self-care behaviours toward diabetes}

The overall prevalence of poor self-care behaviours toward DM was $49.1 \%$ (95\%CI: 43.5-54.7\%). Poor selfcare behaviours was statistically different by level of education, family history of DM, adherence to medications, having glucometer at home and history of alcohol consumption. Table 3 presents binary logistic regression results of factors independently associated with poor selfcare behaviours.

Respondents with lower educational level were likely to have poor self-care behaviour than those with higher secondary education $(\mathrm{AOR}=3.1,95 \% \mathrm{CI}: 1.7,5.8)$. Having previous family history of DM was found to be protective against poor self-care behaviours $(\mathrm{AOR}=0.5$, 9\%CI: 0.3-0.9). Compared to respondents with low level of adherence to medications, those with medium level were $60 \%$ less (AOR $=0.4,95 \% \mathrm{CI}$ : 0.3-0.8) likely to have poor self-care behaviours. Interestingly, respondents with glucometers at home were 2.5 times more likely to have poor self-care behaviours than those who did not have $(\mathrm{AOR}=2.5,95 \% \mathrm{CI}: 1.1-5.8)$ glucometers at home. Compared to respondents who did not drink alcohol, those who had history of alcohol consumption were highly likely to have poor self-care behaviours $(\mathrm{AOR}=$ 4.6, 95\%CI: 1.3-15.7).

\section{Level of anti-diabetic adherence to medications}

Table 4 presents levels of adherence to medications by demographic and clinical characteristics. Different levels of adherence to medications were as follows: $24.9 \%$ had low, $37.9 \%$ had medium and $37.2 \%$ had high level of adherence to medications. Of respondents with low level of adherence to medications, $55.8 \%$ had low level of knowledge of diabetes, $63.6 \%$ had poor self-care behaviours and $16.9 \%$ had poor glycemic control level. Similarly, among those who had medium level of adherence to medications, $17.9 \%$ had medium level of knowledge on diabetes, $41.9 \%$ had poor self-care behaviours and $21.4 \%$ had poor glycemic control. Those respondents who had high level of adherence to medications, $35.7 \%$ had high level of diabetes knowledge, $53.9 \%$ had good self-care behaviours and $54.8 \%$ had good glycemic control level.

Table 4 presents results of the multinomial logistic regression analysis of factors associated with adherence to medications. High level of adherence to medications was the reference group. Farmers compared to daily labourers were highly likely (AOR $=6.8,95 \% \mathrm{CI}$ : 1.6-28.8) to have low level of adherence to medications. Respondents with medium level of knowledge of diabetes were $80 \%$ less $(\mathrm{AOR}=0.2,95 \% \mathrm{CI}: 0.1-0.6)$ likely to have low level of adherence to medications. The relative probability of having a low level of adherence to medications among respondents who had good glycaemic control level was higher $(\mathrm{AOR}=3.3$, 95\%CI: 1.5-7.2) than those who had poor glycaemic control level. The relative probability of having a medium level of adherence to medications among respondents who had BMI between 18 and $25 \mathrm{~kg} / \mathrm{m}^{2}$ was significantly higher (AOR $=3.4,95 \% \mathrm{CI}$ : 1.2-9.9) than those who had $30 \mathrm{~kg} / \mathrm{m}^{2}$ and above. Good glycaemic control level was significantly associated with medium level of adherence to medications $(\mathrm{AOR}=2.8$, 95\%CI: 1.5-5.3).

\section{Discussion}

Diabetes is a chronic condition with many complications, and its management would need sufficient levels of knowledge, self-care behaviours and adherence to medications [17, 24]. For effective management and in order to have good glycemic control, patients need to have adequate levels of knowledge of diabetes regarding self-care, a concept that can foster adherence to medications, good dietary pattern and physical activity [11, 25]. Very few studies have addressed the importance of 
Table 2 Multinomial logistic regression analyses findings of factors associated with knowledge on diabetes among T2DM patients JUTH, 2014

\begin{tabular}{|c|c|c|c|c|c|c|c|c|}
\hline \multirow[t]{2}{*}{ Variable } & & \multicolumn{3}{|c|}{ Knowledge, n (\%) $n=309$} & \multicolumn{2}{|c|}{ Low versus High } & \multicolumn{2}{|c|}{ Medium versus High } \\
\hline & & Low $(n=139)$ & Medium $(n=62)$ & High $(n=108)$ & COR $(95 \% \mathrm{Cl})$ & AOR $(95 \% \mathrm{Cl})$ & COR $(95 \% \mathrm{Cl})$ & AOR $(95 \% \mathrm{Cl})$ \\
\hline \multirow[t]{2}{*}{ Sex } & Male & $89(64)$ & $38(61.3)$ & $62(57.4)$ & $1.3(0.8,2.2)$ & - & $1.2(0.6,2.2)$ & - \\
\hline & Female & $50(36)$ & $24(38.7)$ & $46(42.6)$ & 1 & - & 1 & - \\
\hline \multirow[t]{3}{*}{ Age } & $<40$ years & $5(3.8)$ & $2(3.4)$ & $5(5.1)$ & $0.5(0.1,1.9)$ & - & $0.5(0.1,3.1)$ & - \\
\hline & $40-60$ years & $80(61.1)$ & $39(66.1)$ & $69(70.4)$ & $0.6(0.3,1.1)$ & - & $0.8(0.4,1.6)$ & - \\
\hline & $\begin{array}{l}>60 \text { years } \\
\text { Missing }\end{array}$ & $\begin{array}{l}46(35.1) \\
8\end{array}$ & $\begin{array}{l}18(30.5) \\
4\end{array}$ & $\begin{array}{l}24(24.5) \\
10\end{array}$ & 1 & - & 1 & - \\
\hline \multirow[t]{3}{*}{ Marital status } & Married & $111(79.9)$ & $52(83.9)$ & $88(81.5)$ & $1.1(0.5,2.4)$ & $0.9(0.3,2.3)$ & $1.2(0.5,3.1)$ & $0.7(0.2,2.4)$ \\
\hline & Single & $12(8.6)$ & $3(4.8)$ & $6(5.5)$ & $1.8(0.5,5.9)$ & $1.6(0.4,7)$ & $1(0.2,5.2)$ & $0.6(0.1,3.9)$ \\
\hline & Widow/er & $16(11.5)$ & $7(11.3)$ & $14(13)$ & 1 & 1 & 1 & 1 \\
\hline \multirow[t]{3}{*}{ Level of Education } & Illiterate & $60(43.2)$ & $18(29)$ & $31(28.7)$ & $2.6(1.3,4.9)^{*}$ & $3.1(1.03,9.3)^{*}$ & $0.9(0.4,2.04)$ & $0.4(0.1,1.7)$ \\
\hline & Primary & $51(36.7)$ & $21(33.9)$ & $40(37)$ & $1.6(0.9,3.2)$ & $1.9(0.8,4.9)$ & $0.8(0.4,1.8)$ & $0.4(0.1,1.3)$ \\
\hline & $2^{0}$ and above & $28(20.1)$ & $23(37.1)$ & $37(34.3)$ & 1 & 1 & 1 & 1 \\
\hline \multirow[t]{5}{*}{ Occupation } & Employed & $28(20.1)$ & $16(25.8)$ & $28(25.9)$ & $0.8(0.3,1.8)$ & $0.6(0.2,1.8)$ & $2(0.6,7.1)$ & $1.4(0.3,6.2)$ \\
\hline & Unemployed & $31(22.3)$ & $18(29)$ & $29(26.9)$ & $0.8(0.3,1.9)$ & $0.5(0.2,1.4)$ & $2.1(0.6,7.6)$ & $3.3(0.7,16.1)$ \\
\hline & Merchant & $14(10.1)$ & $6(9.7)$ & $9(8.3)$ & $1.2(0.4,3.6)$ & $0.7(0.2,2.7)$ & $2.3(0.5,10.6)$ & $3.8(0.7,22.2)$ \\
\hline & Farmer & $48(34.5)$ & $18(29)$ & $28(25.9)$ & $1.3(0.6,3.09)$ & $0.5(0.2,1.6)$ & $2.3(0.6,7.9)$ & $2.4(0.5,12.1)$ \\
\hline & Daily labor & $18(12.9)$ & $4(6.5)$ & $14(13)$ & 1 & 1 & 1 & 1 \\
\hline \multirow[t]{2}{*}{ Family/social support } & Yes & $85(61.2)$ & $29(46.8)$ & $61(56.5)$ & $1.2(0.7,2)$ & $0.9(0.5,1.7)$ & $0.6(0.4,1.3)$ & $0.6(0.3,1.3)$ \\
\hline & No & $54(38.8)$ & $33(53.2)$ & $47(43.5)$ & 1 & 1 & 1 & 1 \\
\hline \multirow[t]{2}{*}{ DM Family history } & Yes & $38(27.3)$ & $9(14.5)$ & $29(26.9)$ & $1.03(0.6,1.8)$ & $1.3(0.6,2.5)$ & $0.5(0.2,1.06)$ & $0.5(0.2,1.4)$ \\
\hline & No & $101(72.7)$ & $53(85.5)$ & $79(73.1)$ & 1 & 1 & 1 & 1 \\
\hline \multirow[t]{2}{*}{ Glucometer at home } & Yes & $12(8.6)$ & $3(4.8)$ & 15 (13.9) & $0.6(0.3,1.3)$ & $0.5(0.2,1.3)$ & $0.3(0.09,1.1)$ & $0.3(0.07,1.3)$ \\
\hline & No & $127(91.4)$ & $59(95.2)$ & $93(86.1)$ & 1 & 1 & 1 & 1 \\
\hline \multirow[t]{2}{*}{ Cigarette smoking } & Yes & $10(7.2)$ & $5(8.1)$ & $7(6.5)$ & $1.1(0.4,3)$ & - & $1.2(0.4,4)$ & - \\
\hline & No & 129 (92.8) & $57(91.9)$ & $101(93.5)$ & 1 & - & 1 & - \\
\hline Alcohol drinking & $\begin{array}{l}\text { Yes } \\
\text { No }\end{array}$ & $\begin{array}{l}7(5) \\
132(95)\end{array}$ & $\begin{array}{l}3(4.8) \\
59(95.2)\end{array}$ & $\begin{array}{l}7(6.5) \\
101(93.5)\end{array}$ & $\begin{array}{l}0.8(0.3,2.2) \\
1\end{array}$ & $\begin{array}{l}- \\
-\end{array}$ & $\begin{array}{l}0.7(0.2,2.9) \\
1\end{array}$ & $\begin{array}{l}- \\
-\end{array}$ \\
\hline \multirow[t]{2}{*}{ Khat chewing status } & Yes & $32(23)$ & 19 (30.6) & $26(24.1)$ & $0.9(0.5,1.7)$ & - & $1.4(0.7,2.8)$ & - \\
\hline & No & $107(77)$ & $43(69.4)$ & $82(75.9)$ & 1 & - & 1 & - \\
\hline \multirow[t]{4}{*}{$\mathrm{BMI}$ in $\mathrm{Kg} / \mathrm{m}^{2}$} & $<18$ & $11(7.9)$ & $3(4.8)$ & $3(2.8)$ & $6.9(1.5,32)^{*}$ & $6.4(1.2,34.9)^{*}$ & $2.5(0.4,16)$ & $3.5(0.4,30.1)$ \\
\hline & $18-25$ & $78(56.1)$ & $33(53.2)$ & $50(46.3)$ & $2.9(1.2,7.4)^{*}$ & $2.5(0.9,7)$ & $1.6(0.6,4.7)$ & $2.6(0.8,8.9)$ \\
\hline & $25-30$ & $42(30.2)$ & $20(32.3)$ & $40(37)$ & $1.9(0.8,5.2)$ & $2.4(0.8,6.9)$ & $1.3(0.4,3.7)$ & $2.09(0.6,7.4)$ \\
\hline & $>=30$ & $8(5.8)$ & $6(9.7)$ & 15 (13.9) & 1 & 1 & 1 & 1 \\
\hline \multirow[t]{2}{*}{ Self-care behaviour } & Good & $61(43.9)$ & $36(58.1)$ & $61(56.5)$ & $0.6(0.3,1)$ & $0.5(0.3,0.9)^{*}$ & $1.1(0.6,2)$ & $0.9(0.4,2.09)$ \\
\hline & Poor & $78(56.1)$ & $26(41.9)$ & $47(43.5)$ & 1 & 1 & 1 & 1 \\
\hline \multirow[t]{3}{*}{ Duration of DM in year } & $<5$ & $73(52.5)$ & $41(66.1)$ & $31(28.7)$ & $4.7(2.3,9.5)^{*}$ & $4.2(1.9,9.5)^{*}$ & $9.5(3.3,27.1)^{*}$ & $9.8(3.2,30.2)^{*}$ \\
\hline & $5-10$ & $48(34.5)$ & $16(25.8)$ & $41(38)$ & $2.3(1.2,4.7)^{*}$ & $1.8(0.8,3.9)$ & $2.8(0.9,8.4)$ & $2.5(0.8,8.1)$ \\
\hline & $>10$ & $18(13)$ & $5(8.1)$ & $36(33.3$ & 1 & 1 & 1 & 1 \\
\hline \multirow[t]{2}{*}{ Glycemic control level } & Good & $100(71.9)$ & $38(61.3)$ & $81(75)$ & $1.2(0.7,2)$ & - & $1.9(0.9,3.7)$ & $0.9(0.4,2.09)$ \\
\hline & Poor & $39(28.1)$ & $24(38.7)$ & $27(25)$ & 1 & - & 1 & 1 \\
\hline
\end{tabular}

* Statistically significant at $P$-value $<=0.05$

T2DM type 2 diabetes Mellitus, JUTH Jimma University Teaching Hospital 
Table 3 Factors independently associated with poor self-care behaviours among T2DM patients JUTH, 2014

\begin{tabular}{|c|c|c|c|c|c|}
\hline \multirow[t]{2}{*}{ Variables } & \multicolumn{2}{|c|}{ Self-care behaviour $(n=309)$} & \multirow[b]{2}{*}{ Poor n (\%) } & \multirow[t]{2}{*}{ COR $(95 \% \mathrm{Cl})$} & \multirow{2}{*}{$\begin{array}{l}\text { AOR (95 \% } \\
\text { Cl) }\end{array}$} \\
\hline & & Good n (\%) & & & \\
\hline \multirow[t]{3}{*}{ Education } & Illiterate & $18(20.7)$ & $69(79.3)$ & $2.7(1.5,4.9)$ & $3.1(1.7,5.8)^{*}$ \\
\hline & Primary & $10(45.5)$ & $12(54.5)$ & $1.8(1,3.1)$ & $1.9(1.1,3.6)^{*}$ \\
\hline & $2^{0}$ and above & $31(27.7)$ & $81(72.3)$ & 1 & 1 \\
\hline \multirow[t]{2}{*}{ Family history } & Yes & $31(19.7)$ & $45(29.6)$ & $0.5(0.3,0.9)$ & $0.5(0.3,0.9)^{*}$ \\
\hline & No & $126(80.3)$ & $107(70.4)$ & 1 & 1 \\
\hline \multirow[t]{3}{*}{ Adherence to medications } & High & $62(53.9)$ & $53(46.1)$ & $0.5(0.3,0.9)$ & $0.6(0.3,1.1)$ \\
\hline & Medium & $68(58.1)$ & $49(41.9)$ & $0.4(0.2,0.7)$ & $0.4(0.3,0.8)^{*}$ \\
\hline & Low & $28(36.4)$ & 49 (63.6) & 1 & 1 \\
\hline \multirow[t]{2}{*}{ Have glucometer at home } & Yes & $12(40)$ & $18(60)$ & $1.7(0.8,3.6)$ & $2.5(1.1,5.8)^{*}$ \\
\hline & No & $146(52.3)$ & $133(47.7)$ & 1 & 1 \\
\hline \multirow[t]{2}{*}{ History of alcohol drinking } & Yes & $4(23.5)$ & $13(76.5)$ & $3.6(1.2,11.4)$ & $4.6(1.3,15.7)^{*}$ \\
\hline & No & $154(52.7)$ & $138(47.3)$ & 1 & 1 \\
\hline
\end{tabular}

* Statistically significant at $P$-value $<=0.05$

T2DM, type 2 diabetes Mellitus, JUTH Jimma University Teaching Hospital

knowledge, self-care behaviours and adherence to medications among diabetic patients in resource poor countries including Ethiopia [8, 15].

The findings of the current study conform with results from Asian and African studies that have revealed low level of knowledge of diabetes among participants, who also demonstrated to have poor self-care behaviours and poor adherence to medications [14, 16, 26-28]. However, studies from elsewhere have also reported contrasting findings [25, 29]. We argue that, these differences in findings could be due to differences in study populations as wells as the type of tools used to measures these outcomes. Consistent with the current study's findings, knowledge has a significant effect on self-care behaviours and adherence to medications [30, 31]. As such, these findings inform of the necessity to have consistent diabetic education to address issues related to self-care behaviours and adherence to medications as both are the most cost effective management strategies for DM complications [32]. As the diabetic education alone would not be sufficient for sustained control, comprehensive and effective strategies comprising actions to enforce self-care behaviours such as good dietary patterns, regular physical activity, self-glycemic control and foot care [33] should be designed.

Respondents aged between 40 and 60 years were less likely to have low knowledge level than those in age group older than 60 years. This indicates that older people were at a higher risk and thus there would be a need to develop targeted programs to address inequity that existed between age groups. A significant difference in low level of knowledge of diabetes was observed among illiterates than those who attained higher secondary education. This is not surprising as knowledge is gained through education. This finding was consistent with other studies from United Arab Emirates (UAE) [16] and Bangladesh [14]. Lower education status could end up with low self-management behaviours, lower self-efficacy and lower continuity of care. Thus, as recommendations, measures to improve literacy level would be cost effective to reduce diabetic morbidity and mortality [12, 34]. Lower BMI and short duration of diabetes (less than five years) were significantly associated with level of knowledge and this was supported by findings from Nigeria [35] to UAE [16].

Almost half (49.1\%) of the respondents had poor selfcare behaviours toward DM. Although these figures are lower than the previously reported elsewhere including in North Ethiopia (59 \%) [15], East Ethiopia (60.8 \%) [31] and Kenya (63.2 \%), [28], the magnitude of diabetes in the current study society still denotes diabetes as a significant public health problem. The hypothesise that this variation could be due to the types instruments used in different studies or duration of patients on treatment. It well known that a well instituted diabetes self-care plan lowers glycosylated hemoglobin levels- an indicator that can be used to monitor diabetes [36].

Lower educational level and poor adherence to medications were among the predictors of poor self-care behaviours. This is similar to findings of the previous studies [31, 37, 38], and shows how diabetes education and its application is indispensable for diabetic management [32, 33]. Having family history of DM was found to be protective against poor self-care behaviours, a finding which is not dissimilar with findings of the previous studies $[25,39,40]$. It would be plausible to argue that diabetic patients would share their knowledge, and experiences with families members [25], information that 
Table 4 Multinomial logistic regression analyses findings of factors associated with adherence to medications among T2DM patients JUTH, 2014

\begin{tabular}{|c|c|c|c|c|c|c|c|c|}
\hline \multirow[t]{2}{*}{ Variable } & & \multicolumn{3}{|c|}{ Adherence to medications, n (\%) } & \multicolumn{2}{|c|}{ Low versus High } & \multicolumn{2}{|c|}{ Medium versus High } \\
\hline & & $\begin{array}{l}\text { Low } \\
(n=77)\end{array}$ & $\begin{array}{l}\text { Medium } \\
(n=117)\end{array}$ & $\begin{array}{l}\text { High } \\
(n=115)\end{array}$ & COR (95\%Cl) & AOR $(95 \% \mathrm{Cl})$ & COR $(95 \% \mathrm{Cl})$ & AOR $(95 \% \mathrm{Cl})$ \\
\hline \multirow[t]{2}{*}{ Sex } & Male & $52(67.5)$ & $70(59.8)$ & $67(58.3)$ & $1.5(0.8,2.7)$ & $1.5(0.6,3.8)$ & $1.1(0.6,1.8)$ & $1.5(0.7,3.4)$ \\
\hline & Female & $25(32.5)$ & $47(40.2)$ & $48(41.7)$ & 1 & 1 & 1 & 1 \\
\hline \multirow[t]{3}{*}{ Age } & $<40$ years & $3(4.1)$ & $7(6.4)$ & $2(1.9)$ & $1.8(0.3,11.7)$ & - & $4.6(0.9,23.9)$ & - \\
\hline & $40-60$ years & $42(57.5)$ & $77(70)$ & $69(65.7)$ & $0.7(0.4,1.4)$ & - & $1.5(0.8,2.7)$ & - \\
\hline & $\begin{array}{l}>60 \text { years } \\
\text { Missing }\end{array}$ & $\begin{array}{l}28(38.4) \\
4\end{array}$ & $\begin{array}{l}26(23.6) \\
7\end{array}$ & $\begin{array}{l}34(32.4) \\
10\end{array}$ & 1 & - & 1 & - \\
\hline \multirow[t]{3}{*}{ Marital status } & Married & $66(85.7)$ & $95(81.2)$ & $90(78.3)$ & $1.7(0.6,4.3)$ & - & $1.2(0.6,2.6)$ & - \\
\hline & Single & $4(5.2)$ & $8(6.8)$ & $9(7.8)$ & $1.02(0.2,4.4)$ & - & $1.02(0.3,3.4)$ & - \\
\hline & Widow/er & $7(9.1)$ & $14(12)$ & $16(13.9)$ & 1 & - & 1 & - \\
\hline \multirow[t]{3}{*}{ Level of Education } & Illiterate & $29(37.7)$ & $47(40.2)$ & $33(28.7)$ & $1.9(0.9,4.1)$ & $2.03(0.6,6.8)$ & $1.9(0.9,3.6)$ & $1.01(0.4,2.9)$ \\
\hline & Primary & $30(39)$ & $40(34.2)$ & $42(36.5)$ & $1.6(0.8,3.3)$ & $1.3(0.5,3.8)$ & $1.3(0.7,3.3)$ & $0.7(0.3,1.7)$ \\
\hline & $2^{0}$ and above & $18(23.3)$ & $30(25.6)$ & $40(34.8)$ & 1 & 1 & 1 & 1 \\
\hline \multirow[t]{5}{*}{ Occupation } & Employed & $20(26)$ & $25(21.4)$ & $27(23.5)$ & $2.3(0.8,6.5)$ & $2.9(0.9,9.7)$ & $2.9(1.06,7.9)^{*}$ & $3.1(1.01,9.7)^{*}$ \\
\hline & Unemployed & 15 (19.5) & $33(28.2)$ & $30(26.1)$ & $1.6(0.6,4.5)$ & $2.7(0.7,10.8)$ & $3.5(1.3,9.3)^{*}$ & $8.2(2.2,30.4)^{*}$ \\
\hline & Merchant & $13(16.9)$ & $9(7.7)$ & $7(6.1)$ & $5.8(1.7,20.4)^{*}$ & $6.8(1.6,28.8)^{*}$ & $4(1.09,14.9)^{*}$ & $5.3(1.2,22.8)^{*}$ \\
\hline & Farmer & $22(28.6)$ & $43(36.7)$ & $29(25.2)$ & $2.4(0.9,6.6)$ & $1.6(0.4,5.8)$ & $4.7(1.8,12.3)^{*}$ & $3.8(1.1,12.8)^{*}$ \\
\hline & Daily labor & $7(9)$ & $7(6)$ & $22(19.1)$ & 1 & 1 & 1 & 1 \\
\hline \multirow[t]{2}{*}{ Family/social support } & Yes & $46(59.7)$ & $69(59)$ & $60(52.2)$ & $1.4(0.8,2.4)$ & - & $1.3(0.8,2.2)$ & - \\
\hline & No & $31(40.3)$ & $48(41)$ & $55(47.8)$ & 1 & - & 1 & - \\
\hline \multirow[t]{2}{*}{ DM Family history } & Yes & $18(23.4)$ & $34(29.1)$ & $24(20.9)$ & $1.2(0.6,2.3)$ & $1.1(0.5,2.6)$ & $1.6(0.9,2.8)$ & $1.6(0.8,3.2)$ \\
\hline & No & $59(76.6)$ & $83(70.9)$ & $91(79.1)$ & 1 & 1 & 1 & 1 \\
\hline \multirow[t]{2}{*}{ Glucometer at home } & Yes & $8(10.4)$ & $13(11.1)$ & $9(7.8)$ & $1.4(0.5,3.7)$ & - & $1.4(0.6,3.6)$ & - \\
\hline & No & $69(89.6)$ & $104(88.9)$ & $106(92.2)$ & 1 & - & 1 & - \\
\hline \multirow[t]{2}{*}{ Cigarette smoking } & Yes & $10(13)$ & $4(3.4)$ & $8(7)$ & $1.9(0.8,5.3)$ & $2.3(0.6,8.6)$ & $0.5(0.1,1.6)$ & $0.4(0.1,1.6)$ \\
\hline & No & $67(87)$ & $113(96.6)$ & $107(93)$ & 1 & 1 & 1 & 1 \\
\hline Alcohol drinking & $\begin{array}{l}\text { Yes } \\
\text { No }\end{array}$ & $\begin{array}{l}8(10.4) \\
69(89.6)\end{array}$ & $\begin{array}{l}5(4.3) \\
112(95.7)\end{array}$ & $\begin{array}{l}4(3.5) \\
111(96.5)\end{array}$ & $\begin{array}{l}3.2(0.9,11.1) \\
1\end{array}$ & $\begin{array}{l}2.1(0.5,9.2) \\
1\end{array}$ & $\begin{array}{l}1.2(0.3,4.7) \\
1\end{array}$ & $\begin{array}{l}1.8(0.4,7.9) \\
1\end{array}$ \\
\hline \multirow[t]{2}{*}{ Khat chewing status } & Yes & $18(23.4)$ & $38(32.5)$ & $21(18.3)$ & $1.4(0.7,2.8)$ & $0.8(0.4,2.1)$ & $2.2(1.2,3.9)^{*}$ & $1.9(0.9,3.9)$ \\
\hline & No & $59(76.6)$ & $79(67.5)$ & $94(81.7)$ & 1 & 1 & 1 & 1 \\
\hline \multirow[t]{4}{*}{$\mathrm{BMl}$ in $\mathrm{Kg} / \mathrm{m}^{2}$} & $<18$ & $7(9.1)$ & $6(5.1)$ & $4(3.5)$ & $5.6(1.2,27.4)^{*}$ & $4.9(0.8,31)$ & $3(0.7,13.8)$ & $2.9(0.6,16.3)$ \\
\hline & $18-25$ & $46(59.7)$ & $69(59)$ & $46(40)$ & $3.2(1.1,9.5)^{*}$ & $2.6(0.7,9.1)$ & $3(1.2,7.6)^{*}$ & $3.4(1.2,9.9)^{*}$ \\
\hline & $25-30$ & $19(24.7)$ & $34(29.1)$ & $49(42.6)$ & $1.2(0.4,3.9)$ & $1.3(0.3,4.6)$ & $1.4(0.5,3.6)$ & $1.7(0.6,4.9)$ \\
\hline & $>=30$ & $5(6.5)$ & $8(6.8)$ & $16(13.9)$ & 1 & 1 & 1 & 1 \\
\hline Knowledge & $\begin{array}{l}\text { High } \\
\text { Medium }\end{array}$ & $\begin{array}{l}27(35.1) \\
7(9.1)\end{array}$ & $\begin{array}{l}40(34.2) \\
21(17.9)\end{array}$ & $\begin{array}{l}41(35.7) \\
34(29.6)\end{array}$ & $\begin{array}{l}1.6(0.9,3.1) \\
0.3(0.1,0.8)^{*}\end{array}$ & $\begin{array}{l}1.1(0.5,2.4) \\
0.2(0.1,0.6)^{*}\end{array}$ & $\begin{array}{l}1.4(0.8,2.6) \\
0.6(0.3,1.3)\end{array}$ & $\begin{array}{l}1.4(0.7,2.9) \\
0.5(0.2,1.2)\end{array}$ \\
\hline \multirow[t]{3}{*}{ Self-care } & Low & $43(55.8)$ & $56(47.9)$ & $40(34.8)$ & 1 & 1 & 1 & 1 \\
\hline & Good & $28(36.4)$ & $68(58.1)$ & $62(53.9)$ & $0.5(0.3,0.9)^{*}$ & $0.7(0.3,1.3)$ & $1.2(0.7,1.9)$ & $1.7(0.9,3.1)$ \\
\hline & Poor & $49(63.6)$ & $49(41.9)$ & $53(46.1)$ & 1 & 1 & 1 & 1 \\
\hline \multirow[t]{3}{*}{ Duration of DM in year } & $<5$ & $43(55.8)$ & $54(46.2)$ & $48(41.7)$ & $1.7(0.8,3.7)$ & $2.1(0.8,5.6)$ & $1.2(0.6,2.5)$ & $1.02(0.4,2.4)$ \\
\hline & $5-10$ & $21(27.3)$ & $41(35)$ & $43(37.4)$ & $0.9(0.4,2.2)$ & $0.9(0.4,2.5)$ & $1.04(0.5,2.1)$ & $1.01(0.4,2.3)$ \\
\hline & $>10$ & $13(16.9)$ & $22(18.8)$ & $24(20.9)$ & 1 & 1 & 1 & 1 \\
\hline \multirow[t]{2}{*}{ Glycemic control level } & Good & $64(83.1)$ & 92 (78.6) & $63(54.8)$ & $4.1(2.02,8.2)^{*}$ & $3.3(1.5,7.2)^{*}$ & $3.04(1.7,5.4)^{*}$ & $2.8(1.5,5.3)^{*}$ \\
\hline & Poor & $13(16.9)$ & $25(21.4)$ & $52(45.2)$ & 1 & 1 & 1 & 1 \\
\hline
\end{tabular}


could be used by the newly diagnosed members to improve their conditions through effective self-care behaviours.

The current study also revealed that respondents who had glucometer at home were 2.5 times more likely to have poor self-care behaviours than those who did not. This could be due to the fact that the majority (nearly $90 \%$ ) of the respondents had not been counseled on how to measure self-glucose level using glucometer. Besides, more than $90 \%$ of respondents did not SelfMonitoring Blood Glucose (SMBG) service at home either due to lack of knowledge or scarcity of consumables. Consistent with findings from California [41] to United Kingdom [42], the relative probability of having poor self-care behaviours among respondents who had history of alcohol drinking was also significantly higher than those who did not drink. This is a clue for the inclusion of brief interventions strategy for alcohol in diabetes care.

This study reported that one fourth and two fifth of the respondents had low and medium level of adherence to diabetic medications respectively, the findings which were lower than a study from France [10]. The differences could be explained due to financial problem, management of side effect of the drugs, health care providers' approach during diabetic education and counseling, and general quality of care for diabetic services in Ethiopia [8]. Furthermore, individuals with low socioeconomic status have limited access to education, information and transportation, which are necessary drivers to required necessary services including medications.

In the current study, farmers compared to daily labours were high likely to have lower level of adherence to medications. This could be related with level of education as it was obvious that the majority of the farmers in this study were illiterate compared to daily labourers. In addition, other plausible factors including poor access to health care and allocating less time for self-care management could be barriers to adherence to medications. In contrast to other studies, [13, 43-45], findings from this study revealed that good glycaemic control level was significantly associated with low and medium level of adherence to medications. We hypothesise that these findings could be related to protection provided by participants life styles including being laborers where they would endure significant incidental physical activity and having dietary patterns that are plant based. However, these findings need further exploration.

This study had several limitations which were worth noting. The institutional based nature of the study might not infer for other diabetic patients. Similarly, the nature of cross-sectional study design does not indicate temporal relationship or causality. Self-report of adherence to medications could also be affected by recall bias.
Moreover, selection bias could also have been introduced because patients who are under regular follow-up by the university clinic are likely to be receiving better care and support than those in the lower level clinics. We were unable to use $\mathrm{HbA1c}$, a more accurate than FBG measurement to evaluate glycemic control due to inaccessibility and high cost of the measurement in our country. It is not routinely done as part of the standard care in the study hospital. This limitation is not only affecting our study, but also is a significant challenge for diabetes control in the country as a whole without access to Hb1Ac measurement. Finally, a psychometric study for the three tools: The Diabetes Knowledge Test (DKT), Expanded Version of the Summary of Diabetes Self-Care Activities (SDSCA) and Morisky scale was not conducted.

\section{Conclusion}

In summary, the findings from the current study revealed that a significant number of diabetic patients had low level of knowledge, poor self-care behaviours and low level of adherence to medications. These findings suggest the need to work on integrated interventional management on diabetic knowledge, self-care behaviours and adherence to medications. Education, awareness creation and implementation of good self-care behaviours could be improved as cross cutting interventions. We recommend the inclusion of brief interventions strategy for alcohol in diabetes care. It has been reported that brief interventions to reduce at-risk drinking has the potential to improve diabetic medication adherence and treatment outcome [46]. We also recommend further population based research to explore specific factors such as the association found in this study that indicated that low level of adherence to medications was associated with good control of glycaemia. Where possible, psychometric studies should be conducted as tools to assess diabetic knowledge, self-care behavior and medication adherence.

\section{Additional file}

Additional file 1: Tools for assessing diabetes related knowledge, selfcare behaviours and adherence to medications among diabetic patients in Southwest Ethiopia, 2014. (DOCX $110 \mathrm{~kb}$ )

\section{Abbreviations}

BMI, body mass index; DM, diabetes mellitus; DKT, diabetes knowledge test; FBG, fasting blood glucose; HbA1c, glycosylated hemoglobin; IDFA International Diabetes Federation Atlas; JUTH, Jimma University Teaching Hospital; OHA, oral hypoglycemic agent; SMBG, self-monitoring blood glucose; SDSCA, summary of diabetes self-care activities; T2DM, type-2 diabetes mellitus

\section{Acknowledgments}

The authors are grateful to the respondents and data collectors. This research was funded by Jimma University. 


\section{Funding}

This research was funded by Jimma University and was received by Hailay Gesesew. The funders had no role in study design, data collection and analysis, decision to publish, or preparation of the manuscript.

\section{Availability of data and materials}

The dataset supporting the conclusions of this article is included within the article.

\section{Authors' contributions}

TK involved in designing of the study, data collection, data analysis, drafting and critically reviewing the manuscript. Likewise, $H G, L M$ and TE involved in designing of the study, analysis of the data and critically reviewing the manuscript. All authors read and approved the final manuscript.

\section{Authors' information}

TK is a clinical pharmacist in Dilchora Hospital of Ethiopia. HG is a lecturer of Epidemiology in college of Health Sciences of Jimma University and PhD fellow in Flinders University. LM is a senior lecturer and course coordinator in Faculty of Medicine, Nursing and Health Sciences at Flinders University. TE is associate professor of Clinical Pharmacy in college of Health Sciences of Jimma University. All authors are currently staff members in their respective department.

\section{Competing interests}

The authors declare that they have no competing interest.

\section{Consent for publication}

Not Applicable.

\section{Ethics approval and consent}

Informed consent was obtained from study participants before the commencement of each interview, and no personal identification was registered. There was no any financial compensation or provision for the study participants. The permission to conduct the study was obtained from JUTH and the study was approved by institutional review board (IRB) of college of health sciences at Jimma University, Southwest Ethiopia.

\section{Author details}

'Dilchora Hospital, Diredawa, East Ethiopia. ${ }^{2}$ Department of Epidemiology, College of Health Sciences, Jimma University, Jimma, Ethiopia. ${ }^{3}$ Discipline of Public Health, Faculty of Medicine, Nursing and Health Sciences, Flinders University, Adelaide, Australia. ${ }^{4}$ Department of Clinical Pharmacy, College of Health Sciences, Jimma University, Jimma, Ethiopia.

\section{Received: 7 January 2016 Accepted: 26 May 2016}

\section{Published online: 31 May 2016}

\section{References}

1. Aschner P, Beck-Nielsen H, Bennett P, Boulton A, Colagiuri R. Diabetes and impaired glucose tolerance. 5th ed. Brussels: IDF Diabetes Atlas; 2012.

2. IDF. Diabetes and impaired glucose tolerance. 6th ed. Brussels: Diabetes Atlas; 2013.

3. Harries AD, Satyanarayana S, Kumar AM, Nagaraja SB, Isaakidis P, Malhotra S, Achanta S, Naik B, Wilson N, Zachariah R, et al. Epidemiology and interaction of diabetes mellitus and tuberculosis and challenges for care: a review. Public health action. 2013;3 Suppl 1:S3-9.

4. Whiting DR, Guariguata L, Weil C, Shaw J. IDF diabetes atlas: global estimates of the prevalence of diabetes for 2011 and 2030. Diabetes Res Clin Pract. 2011;94(3):311-21.

5. Wandell PE. Quality of life of patients with diabetes mellitus. An overview of research in primary health care in the Nordic countries. Scand J Prim Health Care. 2005;23(2):68-74

6. Katz ML, Laffel LM, Perrin JM, Kuhlthau K. Impact of type 1 diabetes mellitus on the family is reduced with the medical home, care coordination, and family-centered care. J Pediatr. 2012;160(5):861-7.

7. Bonow RO, Gheorghiade M. The diabetes epidemic: a national and global crisis. Am J Med. 2004;116(Suppl 5A):2s-10.

8. Wabe NT, Angamo MT, Hussein S. Medication adherence in diabetes mellitus and self management practices among type-2 diabetics in Ethiopia. N Am J Med Sci. 2011;3(9):418-23.
9. WHO. World Health Organization. Global health risks: mortality and burden of disease attributable to selected major risks. Geneva; 2009.

10. Tiv M, Viel J-F, Mauny F, Eschwege E, Weill A, Fournier C, Fagot-Campagna A, Penfornis A. Medication adherence in type 2 diabetes: the entred study 2007, a French population-based study. PLoS One. 2012;7(3):e32412.

11. Gautam A, Bhatta DN, Aryal UR. Diabetes related health knowledge, attitude and practice among diabetic patients in Nepal. BMC Endocr Disord. 2015;15:25.

12. Rani PK, Raman R, Subramani S, Perumal G, Kumaramanickavel G, Sharma T. Knowledge of diabetes and diabetic retinopathy among rural populations in India, and the influence of knowledge of diabetic retinopathy on attitude and practice. Rural Remote Health. 2008;8(3):838.

13. Al-Qazaz H, Sulaiman SA, Hassali MA, Shafie AA, Sundram S, Al-Nuri R, Saleem F. Diabetes knowledge, medication adherence and glycemic control among patients with type 2 diabetes. Int J Clin Pharm. 2011:33(6):1028-35.

14. Islam SM, Niessen LW, Seissler J, Ferrari U, Biswas T, Islam A, Lechner A. Diabetes knowledge and glycemic control among patients with type 2 diabetes in Bangladesh. Springer Plus. 2015;4:284.

15. Feleke SA, Alemayehu CM, Adane HT. Assessment of the level and associated factors with knowledge and practice of diabetes mellitus among diabetic patients attending at FelegeHiwot hospital, Northwest Ethiopia. Clinical and Medicine Research. 2013;2(6):110-20.

16. Al-Maskari F, El-Sadig M, Al-Kaabi JM, Afandi B, Nagelkerke N, Yeatts KB. Knowledge, attitude and practices of diabetic patients in the United Arab Emirates. PLoS One. 2013;8(1), e52857.

17. DACA. Standard treatment guideline for primary hospitals. 2nd edn. Addis Ababa; 2010

18. IDF. IDF Clinical Guidelines Task Force: Global guideline for Type 2 diabetes. Brussels; 2012.

19. Kassahun T, Eshetie T, Gesesew H. Factors associated with glycemic control among adult patients with type 2 diabetes mellitus: a crosssectional survey in Ethiopia. BMC Research Notes. 2016:9:78.

20. West JD, Goldberg KL. Diabetes self -care knowledge among outpatients at a veterans affairs medical center. Am J Health Syst Pharm. 2002;59(9):849-52.

21. Fitzgerald JT, Funnell MM, Hess GE, Barr PA, Anderson RM, Hiss RG, Davis WK. The reliability and validity of a brief diabetes knowledge test. Diabetes Care. 1998;21(5):706-10.

22. Toobert DJ, Hampson SE, Glasgow RE. The summary of diabetes self-care activities measure: results from 7 studies and a revised scale. Diabetes Care. 2000;23(7):943-50.

23. Morisky DE, Green LW, Levine DM. Concurrent and predictive validity of a selfreported measure of medication adherence. Med Care. 1986;24(1):67-74.

24. ADA. Standards of medical care in diabetes-2013. Diabetes Care. 2013;36 Suppl 1:S11-66

25. Saleh F, Mumu SJ, Ara F, Begum HA, Ali L. Knowledge and self-care practices regarding diabetes among newly diagnosed type 2 diabetics in Bangladesh: a cross-sectional study. BMC Public Health. 2012;12:1112.

26. Demaio AR, Dugee O, de Courten M, Bygbjerg IC, Enkhtuya P, Meyrowitsch DW. Exploring knowledge, attitudes, and practices related to alcohol in Mongolia: a national population-based survey. BMC Public Health. 2013;13:178.

27. Shah VN, Kamdar PK, Shah N. Assessing the knowledge, attitudes and practice of type 2 diabetes among patients of Saurashtra region, Gujarat. International journal of diabetes in developing countries. 2009;29(3):118-22.

28. Kiberenge MW, Ndegwa ZM, Njenga EW, Muchemi EW. Knowledge, attitude and practices related to diabetes among community members in four provinces in Kenya: a cross-sectional study. Pan Afr Med J. 2010;7:2.

29. Gul N. Knowledge, attitudes and practices of type 2 diabetic patients. J Ayub Med Coll Abbottabad. 2010;22(3):128-31.

30. Hwang B, Moser DK, Dracup K. Knowledge is insufficient for self-care among heart failure patients with psychological distress. Health Psychol. 2014;33(7): 588-96.

31. Ayele K, Tesfa B, Abebe L, Tilahun T, Girma E. Self care behavior among patients with diabetes in Harari, Eastern Ethiopia. PLoS One. 2012;7(4):e35515

32. Shrivastava SR, Shrivastava PS, Ramasamy J. Role of self-care in management of diabetes mellitus. Journal of diabetes and metabolic disorders. 2013;12(1):14.

33. Glasgow RE, Strycker LA. Preventive care practices for diabetes management in two primary care samples. Am J Prev Med. 2000;19(1):9-14

34. Getahun H, Gunneberg C, Granich R, Nunn P. HIV infection-associated tuberculosis: the epidemiology and the response. Clin Infect Dis. 2010;50 Suppl 3:S201-7. 
35. Jackson IL, Adibe MO, Okonta MJ, Ukwe CV. Knowledge of self-care among type 2 diabetes patients in two states of Nigeria. Pharm Pract. 2014;12(3):404.

36. Glasgow RE, Hiss RG, Anderson RM, Friedman NM, Hayward RA, Marrero DG, Taylor CB, Vinicor F. Report of the health care delivery work group: behavioral research related to the establishment of a chronic disease model for diabetes care. Diabetes Care. 2001;24(1):124-30.

37. Bai YL, Chiou CP, Chang YY. Self-care behaviour and related factors in older people with Type 2 diabetes. J Clin Nurs. 2009;18(23):3308-15.

38. Huang M, Zhao R, Li S, Jiang X. Self-management behavior in patients with type 2 diabetes: a cross-sectional survey in western urban China. PLoS One. 2014;9(4), e95138.

39. Albright TL, Parchman M, Burge SK. Predictors of self-care behavior in adults with type 2 diabetes: an RRNeST study. Fam Med. 2001;33(5):354-60.

40. Baptiste-Roberts K, Gary TL, Beckles GLA, Gregg EW, Owens M, Porterfield D, Engelgau MM. Family history of diabetes, awareness of risk factors, and health behaviors among African Americans. Am J Public Health. 2007;97(5): 907-12.

41. Ahmed AT, Karter AJ, Liu J. Alcohol consumption is inversely associated with adherence to diabetes self-care behaviours. Diabet Med. 2006;23(7): 795-802.

42. Knott, Katy E. Alcohol consumption and adherence to self-care behaviours in Type 2 diabetes; the inclusion of Brief Interventions for alcohol in diabetes care. UK: University of Leicester; 2013

43. Mayberry LS, Osborn CY. Family support, medication adherence, and glycemic control among adults with type 2 diabetes. Diabetes Care. 2012; 35(6):1239-45.

44. Stewart SM, Lee PWH, Waller D, Hughes CW, Low LCK, Kennard BD, Cheng A, Huen K-F. A follow-Up study of adherence and glycemic control among Hong Kong youths with diabetes. J Pediatr Psychol. 2003;28(1):67-79.

45. Rhee MK, Slocum W, Ziemer DC, Culler SD, Cook CB, El-Kebbi IM, Gallina DL, Barnes C, Phillips LS. Patient adherence improves glycemic control. Diabetes Educ. 2005;31(2):240-50.

46. Engler PA, Ramsey SE, Smith RJ. Alcohol use of diabetes patients: the need for assessment and intervention. Acta Diabetol. 2013;50(2):93-9.

\section{Submit your next manuscript to BioMed Central and we will help you at every step:}

- We accept pre-submission inquiries

- Our selector tool helps you to find the most relevant journal

- We provide round the clock customer support

- Convenient online submission

- Thorough peer review

- Inclusion in PubMed and all major indexing services

- Maximum visibility for your research

Submit your manuscript at www.biomedcentral.com/submit

) Biomed Central 